\title{
Incidentally Detected Renal Cell Carcinoma in Non-Functioning Kidney due to Renal Pelvic Stone Disease: A Case Report
}

\author{
Authors \\ Talib Hussain ${ }^{1 *}$, Feroz Ahmad², Sanjeev Singh ${ }^{3}$, Javid Iqbal $^{4}$ \\ ${ }^{1}$ Lecturer, ${ }^{2}$ Registrar, ${ }^{3}$ Post Graduate, ${ }^{4}$ Lecturer \\ Department of Surgery, Government Medical College Jammu, Jammu and Kashmir, India \\ *Corresponding author \\ Talib Hussain \\ Quarter number C7, Medical Enclave, Opposite K C Cinema, Bakshi Nagar, Jammu 180001 \\ Jammu and Kashmir, India
}

\begin{abstract}
The causes of non-functioning kidney includes stones, PUJ obstruction, infections, trauma etc. Simple nephrectomy is the answer for a non-functioning kidney. The urothelial tumors of renal pelvis and ureter can be associated with long standing calculi and subsequent chronic irritation. But, the renal cell carcinoma is usually not associated with renal calculi. We are reporting a case of incidentally detected renal cell carcinoma in a non-functioning kidney specimen.
\end{abstract}

Keywords: Simple nephrectomy, squamous cell carcinoma, transitional cell carcinoma, renal cell carcinoma, Histopathological examination.

\section{Introduction}

Simple nephrectomy is the treatment for non functioning kidney, which is commonly as a result of long standing staghorn renal calculi complicated with hydronephrosis or pyonephrosis. One can be surprised after getting histopathology report showing malignancy in a simple nephrectomy specimen which was done for a benign pathology. The number of studies and case reports reporting tumors in specimens from patients undergoing nephrectomy for non-functioning kidney due to kidney stones is limited ${ }^{1}$. The squamous cell carcinoma (SCC) and transitional cell carcinoma (TCC) of renal pelvis can be associated with renal stones secondary to chronic bacterial infection and chronic irritation, but renal cell carcinoma (RCC) is usually not associated with renal stones. Here we report a case of renal cell carcinoma diagnosed on histopathology of non-fuctioning kidney due to staghorn pelvic stone.

\section{Case Report}

An 80 yrs old male patient, farmer by occupation presented with complaints of pain left upper abdomen on and off for 02 yrs. Examination of abdomen was unremarkable. His blood group was A +ve. Haemogram was normal. Urine R/E revealed microscopic hematuria. The blood urea was 76 $\mathrm{mg} / \mathrm{dl}$ and creatinine was $2.48 \mathrm{mg} / \mathrm{dl}$.

The plain x-ray KUB showed a large staghorn calcular shadow of about $52.6 \times 31.5 \mathrm{~mm}$ in left renal 


\section{JMSCR Vol||07||Issue\|11||Page 732-735||November}

area and two calcular shadows of about $8.6 \times 6.3 \mathrm{~mm}$ \& $12.5 \times 6.5 \mathrm{~mm}$ in right renal area. On ultrasound abdomen, left kidney measured $20.19 \times 8.52 \mathrm{~cm}$ in size, grossly hydronephrotic pelvicalyceal system with no evidence of cortical tissue (hydronephrotic sac) with loss of corticomedullary differentiation with large staghorn calculus of $5.39 \mathrm{~cm}$ in pelvis.

The right kidney measured $11.02 \times 4.6 \mathrm{~cm}$ in size, two calculi of $10 \mathrm{~mm}$ and $9 \mathrm{~mm}$ in superior calyx without any obstructive changes with normal cortical thickness and normal corticomedullary differentiation. Diethylene Triamine Penta-acetic Acid (DTPA) scan revealed non-functioning left kidney with GFR of $0 \mathrm{ml} / \mathrm{min}$ and split function of $0 \%$. The right kidney normal in site, size, shape, preserved perfusion and parenchymal uptake with GFR of $48 \mathrm{ml} / \mathrm{min} / 1.73 \mathrm{~m}^{2} \mathrm{BSA}$ (Figure 1).

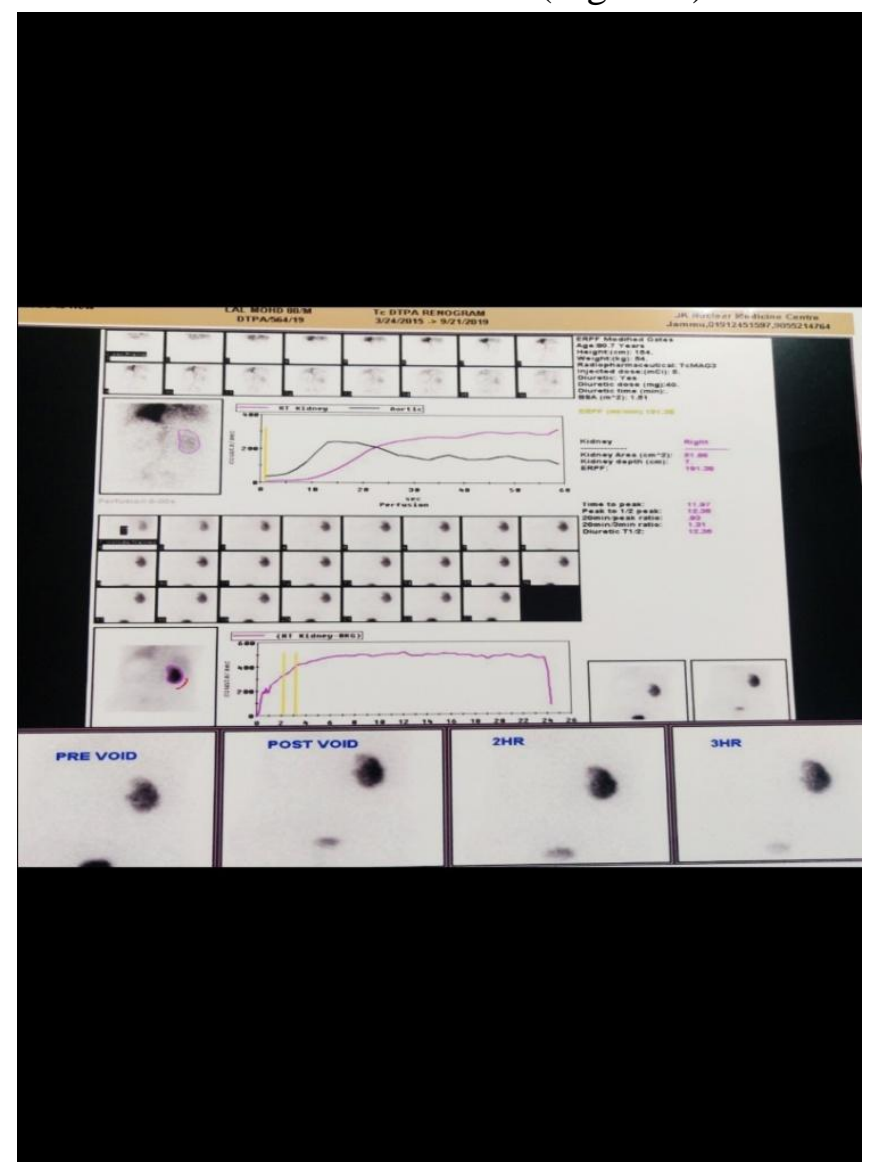

Figure 1: DTPA scan showing non-functioning left kidney.

Left nephrectomy was performed for left nonfunctioning kidney via flank approach. Intraoperatively left kidney was about $20 \times 10 \mathrm{~cm}$ in size, grossly hydronephrotic with dense surrounding adhesions with enlarged hilar lymph nodes. On gross examination of specimen, kidney was hydronephrotic with about $5 \times 5 \mathrm{~cm}$ staghorn pelvic calculus with massively dilated pelvicalyceal system with loss of corticomedullary junction with about $5 \mathrm{~cm}$ greyish growth in mid zone (Figure 2 and 3 ).

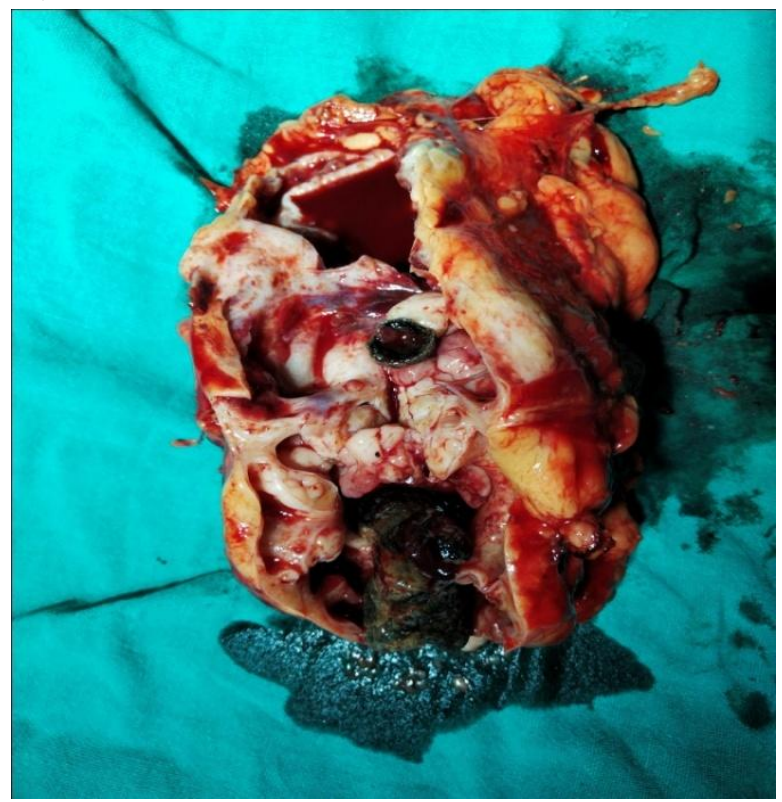

Figure 2: Left nephrectomy specimen showing hydronephrosis, growth in mid zone and large pelvic stone.

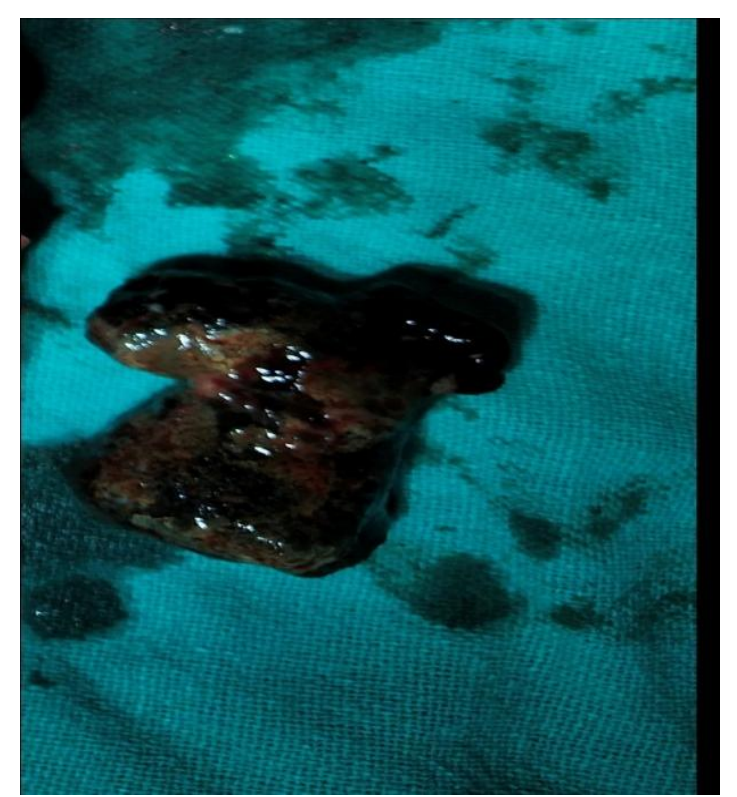

Figure 3: Large stone from pelvis of left kidney.

The histopathology showed renal cell carcinoma (Furhman Nuclear Grade 3) infiltrating into adjacent calyceal system, perirenal fat and blood vessels with gross hydronephritis and compression atrophy 
(Figure 4). All seven lymph nodes showed metastatic deposits.

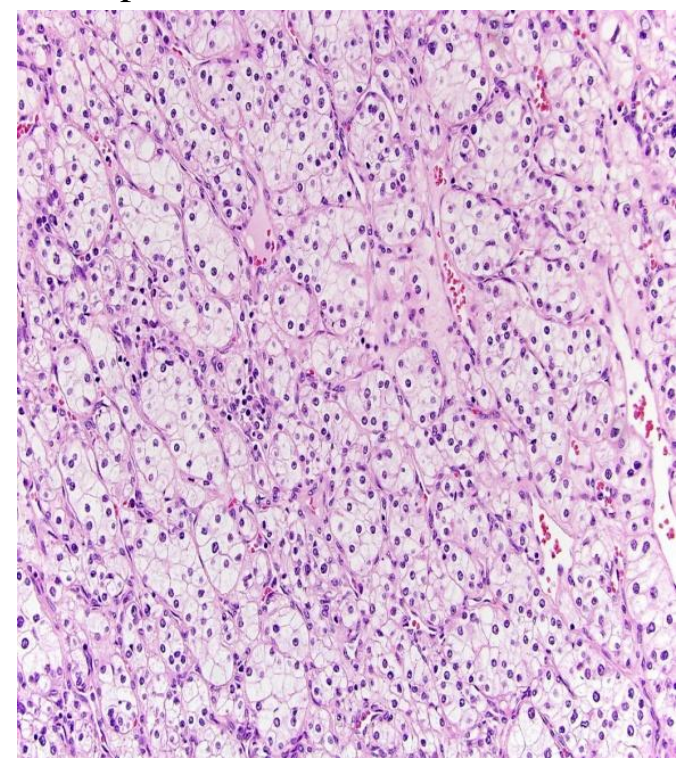

Figure 4: HPE of left nephrectomy specimen showing renal cell carcinoma.

The post operative course was uneventful, with blood urea of $52 \mathrm{mg} / \mathrm{dl}$ and creatinine of $1.42 \mathrm{mg} / \mathrm{dl}$ on 3rd post operative day.

\section{Discussion}

The simple nephrectomy is an important adjunct in the comprehensive management of the unilateral non-functioning kidney due to stones, obstruction, infection, trauma, nephrosclerosis, vesicoureteral reflux, polycystic kidney or congenital dysplasia. The specimen is always to be sent for histopathology examination. The subsequent report may surprisingly reveal a malignancy. The long standing staghorn calculus is one of the etiologies for the development of squamous cell carcinoma and transitional cell carcinoma of renal pelvis ${ }^{2^{-}} 4$. The association of co-existing urinary stone and squamous cell carcinoma varies between $18 \%$ in US to $100 \%$ in Hong Kong. Chronic irritation induced by staghorn calculus superimposed by bacterial infection is believed to result in squamous metaplasia and subsequent development of leukoplakia and neoplasia in the urothelium ${ }^{5}-10$. Due to non specific symptoms of flank pain, a renal tumor usually remains unsuspected and further radiological evaluation such as computerized tomography $(\mathrm{CT})$ is not done routinely in every case of renal stones. So, malignancy should always be suspected in a case of non-functioning kidney due to long standing renal calculi.

\section{Conclusion}

There should be a high index of suspicion of malignancy in a non-functioning kidney, particularly due to long standing pelvic staghorn calculi. Moreover, CECT abdomen may also be considered in the patients of non-functioning kidney with normal renal function tests.

\section{References}

1. Sisodia SM, Khan WAZA, Bhavsar SP. Incidental primary papillary mucinous adenocarcinoma of the renal pelvis in a case of non-functioning kidney due to chronic pyelonephritis and pelvic calculus. Saudi J Kidney Dis Transpl 2012;23:592-593.

2. Blacher EJ, Johnson DE, Abdul-Karim FW, Ayala AG. Squamous cell carcinoma of renal pelvis. Urology 1985;25(2):124-126.

3. Godec CJ, Murrah VA. Simultaneous occurrence of transitional cell carcinoma and urothelial adenocarcinoma associated with xanthogranulomatous pyelonephritis. Urology 1985;26(4):412-415.

4. Spires SE, Banks ER, Cibull ML et al. Adenocarcinoma of renal pelvis. Archives of Pathology and Laboratory Medicine. 1993;117(11):1156-1160.

5. Li MK, Cheung WL. Squamous cell carcinoma of the renal pelvis. Journal of Urology 1987;138(2):269-271.

6. Lee TY, Ko SF, Wan YL, et al. Renal squamous cell carcinoma: CT findings and clinical significance. Abdominal Imaging 1998;23(2):203-208.

7. Holmang S, Lele SM, Johansson SL. Squamous cell carcinoma of the renal pelvis and ureter: incidence, symptoms, treatment and outcome. Journal of Urology 2007;178(1):51-56.

8. Busby JE, Brown GA, Tamboli P, et al. Upper urinary tract tumors with 
nontransitional histology: a single-center experience. Urology 2006;67(3):518-523.

9. Gahagan HQ, Reed WK. Squamous cell carcinoma of the renal pelvis. Three case reports and review of the literature. Journal of Urology 1949;62:139-151.

10. Karabulut A, Emir L, Gonultas M, Incel N, Germiyanoglu C, Erol D. Squamous cell carcinoma located in the renal caliceal system: a case report and review of the literature. Turkish Journal of Cancer 2002;32(1):20-24. 